\title{
An Assessment of Some Recent Criticisms of the U.S. Airline Industry
}

\author{
DARIN LEE
}

LECG, LLC

\begin{abstract}
This article reviews a recent paper by Brock (2000) analyzing developments in the airline industry. Using Department of Transportation data, we attempt to verify a number of assertions made by Brock regarding changes in industry concentration and prices throughout the 1990s. We also compare a number of Brock's other concerns regarding the industry to well-known findings from the airline economics literature.
\end{abstract}

\section{Introduction}

Few industries have received more attention from economists over the past decade than the U.S. airline industry. The bulk of recent studies have focused on specific questions of competitive (or anti-competitive) behavior such as price discrimination, the impact of huband-spoke networks, or the effects of international marketing agreements (to name a few). In contrast, few recent articles have attempted to analyze or evaluate the industry's overall structure and performance throughout the 1990s. ${ }^{1}$ One recent exception is Brock (2000) who cites three main developments in the airline industry: (1) increasing concentration expanded through the proliferation of domestic and international alliances; (2) frequent predatory pricing behavior by network airlines aimed at low-cost independent airlines; and (3) increasing occurrences of tacitly collusive pricing by network airlines. In this article, we attempt to confirm a number of Brock's assertions. Unlike Brock however, we base our analysis on data reported to the U.S. Department of Transportation (DOT). ${ }^{2}$ In general, we find that virtually all of Brock's concerns regarding the airline industry are either misplaced or rely on data which do not accurately reflect the true state of competition in

\footnotetext{
* Mailing Address. 350 Massachusetts Ave., Suite 300, Cambridge, MA, 02139. Tel: (617)-761-0108. Email: Darin_Lee@lecg.com. The author thanks Dan Kasper for helpful comments.

${ }^{1}$ A number of earlier studies evaluated the structure, conduct and performance of the industry in the years directly following deregulation. For example, Evans \& Kessides (1993) study a number of concentration and price metrics between 1978-1988, Borenstein (1992) provides an overview of the evolving market structure as well as other factors important in the marketing and distribution of airline tickets, and Morrison \& Winston (1995) provide a detailed analysis of numerous aspects of the industry through 1993.

${ }^{2}$ In particular, our analysis of industry market shares and prices is based on the DOT's DB1A Database of Origin and Destination passengers. This dataset is a 10\% sample of all passengers carried by U.S. Scheduled Carriers and is the data source most commonly relied upon by academic and non-academic economists studying the airline industry. In contrast, Brock (2000) bases the bulk of his findings on data from various investment bank or newspaper reports.
} 
the industry. In particular, our analysis shows little evidence of increasing industry concentration over the past decade. Moreover, where Brock finds evidence of increasing real prices for airline service industry-wide, our analysis indicates that nominal prices have in fact declined slightly since 1990, and thus, real prices have fallen substantially. Finally, we show that many of Brock's other concerns (i.e. regarding the proliferation of global alliances or allegations of predatory pricing) have either been refuted in court decisions or have been found to be pro-competitive in the transportation economics literature.

\section{Changes in industry concentration}

Brock's analysis of the U.S. airline industry begins with the assertion that the national market shares of the large network airlines has experienced a marked increase over the past decade. In particular, Brock's Table I finds that the "Big Five" carriers (Delta, United, American, US Airways, and Northwest) accounted for roughly two-thirds of all U.S. enplanements in 1997. This analysis of industry concentration is misleading however, since it is based on enplaned rather than Origin and Destination ("O\&D") passengers. Whereas O\&D passengers are based on the start (i.e. origin) and end (i.e. destination) point of passengers' journeys, enplaned passengers count each time a passenger boards an aircraft. Since network airlines carry a significant proportion of their passengers on a connecting rather than non-stop basis, the use of passenger enplanements to calculate market shares is misleading, as it effectively double-counts connecting passengers. For example, in calculating national market shares, Brock's approach would consider a Northwest Airlines passenger travelling from Boston to San Francisco with a connection in Detroit as two separate passengers, whereas a non-stop passenger travelling on American between the same origin (Boston) and destination (San Francisco) would count as a single passenger.

Table 1 summarizes the national market shares of O\&D passengers for the seven largest network carriers and Southwest Airlines between 1990 and 2001. Although our data do not allow us to provide a direct comparison to Brock's 1987 figures in his Table I, we find that the combined market share of the "Big Five" network airlines peaked in 1992 and has been declining since. Moreover, we find that Brock overstates the market share of the "Big Five" in 1997 by ten percentage points and understates that of Southwest by 5.7 percentage points.

Thus, although Brock correctly notes that the combined share of the remaining "independents" (which he defines as all airlines except the network airlines and Southwest) has declined over the past decade, he incorrectly attributes this decline to the increased market share of the network airlines. To the contrary, Table 1 illustrates that this decline has largely been the result of the dramatic growth of Southwest Airlines relative to the rest of the industry. Indeed, Southwest more than doubled its national market share between 1990-2001, and in doing so, has become the largest U.S. airline in terms of O\&D passengers. 


\begin{tabular}{lcccccccccccc}
\hline \hline & 1990 & 1991 & 1992 & 1993 & 1994 & 1995 & 1996 & 1997 & 1998 & 1999 & 2000 & 2001 \\
\cline { 2 - 11 } American & 14.8 & 15.3 & 16.2 & 14.7 & 12.7 & 11.5 & 11.0 & 10.6 & 10.8 & 10.4 & 10.9 & 10.6 \\
Continental & 6.8 & 7.4 & 7.4 & 7.3 & 8.3 & 7.2 & 6.5 & 6.6 & 7.0 & 6.9 & 6.7 & 6.9 \\
Delta & 12.6 & 15.0 & 15.5 & 15.0 & 14.8 & 13.4 & 14.8 & 15.7 & 16.2 & 15.9 & 16.1 & 15.1 \\
Northwest & 7.1 & 7.3 & 7.5 & 7.3 & 7.1 & 7.4 & 7.5 & 7.6 & 7.0 & 7.6 & 7.6 & 7.5 \\
United & 11.5 & 12.8 & 12.7 & 11.8 & 11.2 & 11.9 & 11.9 & 12.1 & 13.2 & 12.7 & 11.7 & 11.2 \\
US Airways & 14.0 & 13.1 & 12.4 & 11.8 & 12.3 & 10.7 & 10.1 & 10.7 & 10.7 & 10.2 & 10.4 & 10.6 \\
TWA & 3.9 & 3.8 & 4.1 & 3.6 & 3.7 & 3.6 & 3.5 & 3.6 & 3.9 & 3.8 & 3.8 & 3.5 \\
Network Airlines & 70.8 & 74.7 & 75.8 & 71.6 & 70.2 & 65.6 & 65.4 & 66.9 & 68.7 & 67.5 & 67.3 & 65.5 \\
"Big Five" & 60.1 & 63.5 & 64.3 & 60.6 & 58.2 & 54.9 & 55.4 & 56.7 & 57.8 & 56.8 & 56.7 & 55.0 \\
& & & & & & & & & & & & \\
Southwest & 7.0 & 8.2 & 9.6 & 11.3 & 12.7 & 13.6 & 14.1 & 13.8 & 13.7 & 14.3 & 14.9 & 15.7 \\
Other Carriers & 22.2 & 17.1 & 14.6 & 17.0 & 17.1 & 20.8 & 20.5 & 19.3 & 17.5 & 18.2 & 17.8 & 18.8 \\
Total & 100.0 & 100.0 & 100.0 & 100.0 & 100.0 & 100.0 & 100.0 & 100.0 & 100.0 & 100.0 & 100.0 & 100.0 \\
\hline
\end{tabular}

Table 1: National market shares $(\%)$

Notes: All domestic passengers, excluding frequent flyer and interline passengers. The "Big Five" carriers are American, Delta, Northwest, United and US Airways. TWA became a wholly owned subsidiary of American in April of 2001. Data for 2001 is for the first two quarters. Source: U.S. DOT DB1A database.

Brock's analysis of local and regional market shares (Table III and Table IV) suffers from the same conceptual flaw. In particular, Brock relies on enplaned passenger data to show that many hub carriers have market shares between $70 \%$ and $94 \%$ at their respective hubs. These figures however, are widely recognized as misleading since they count flow passengers (i.e., those who are making a connection) in addition to those who are beginning or ending their journey at that airport. ${ }^{3}$ Thus, by Brock's analysis, a US Airways passenger travelling from New York to Denver via Charlotte would be counted in computing US Airways' market share for passengers travelling to and from Charlotte. Table 2 illustrates the degree to which the market share figures in Brock's Table IV have been overstated as a result of using enplaned rather than O\&D passengers. For comparative purposes, Table 2 also reports the 2001 O\&D market shares.

Excluding Houston-Hobby (which generates very few flow passengers), Brock's Table $I V$ overstates the market share of the largest carrier by an average of 23.6 percentage points. In sum, Brock's analysis of industry concentration systematically overstates the appropriate market share figures of network carriers by using enplaned rather than O\&D passengers, and in doing so, mischaracterizes structural changes in the industry over the past decade.

\footnotetext{
3 The use of enplaned rather than O\&D passengers to inflate market share figures has also been noted by the courts. For example, in his Summary Judgement ruling in U.S. vs. AMR Corporation (Case No. 99-1180JTM), Judge Thomas Marten noted that "the cited evidence looks at all DFW passenger, including those merely passing through the airport. As a result, it directly overstates the market share of American, which operates at DFW as a hub."
} 


\begin{tabular}{llcccc}
\hline \hline & & \multicolumn{4}{c}{ Market Share (\%) } \\
\cline { 3 - 5 } Airport & Largest Carrier & $\begin{array}{r}1997 \text { (Brock) } \\
(\mathrm{A})\end{array}$ & $\begin{array}{c}1997 \text { O\&D } \\
(\mathrm{B})\end{array}$ & $\begin{array}{c}\text { Difference } \\
(\mathrm{A}) \text {-(B) }\end{array}$ & 2001 O\&D \\
\hline Cincinnati & Delta & 94.1 & 60.4 & 33.7 & 74.7 \\
Charlotte & US Airways & 92.3 & 63.4 & 28.9 & 66.6 \\
Pittsburgh & US Airways & 89.4 & 71.2 & 18.2 & 65.1 \\
Minneapolis & Northwest & 84.5 & 65.7 & 18.8 & 61.1 \\
Houston Hobby & Southwest & 80.8 & 80.0 & 0.8 & 81.1 \\
Detroit & Northwest & 80.4 & 60.4 & 20.0 & 54.4 \\
Houston Intercontinental & Continental & 78.6 & 63.4 & 15.2 & 65.6 \\
Memphis & Northwest & 78.5 & 50.9 & 27.6 & 49.6 \\
Salt Lake City & Delta & 76.8 & 51.1 & 25.7 & 47.6 \\
St. Louis & TWA & 71.0 & 47.0 & 24.0 & 46.5 \\
\hline
\end{tabular}

\section{Table 2: Market shares at select U.S airports}

Notes: 2001 data is for the first two quarters. Domestic revenue passengers excluding interline passengers. Source: U.S. DOT DB1A database and Brock (2000) Table IV.

\section{Proliferation of Alliances}

Brock also expresses concerns regarding the proliferation of international alliances, noting that "Globally, the majors appear to be extending and replicating their dominance of the American market through a proliferation of "joint ventures," "alliances" and partnership pacts affiliating them with the rest of the world's very largest carriers." However, Brock fails to acknowledge the growing body of both theoretical and empirical literature documenting the welfare benefits of these very alliances. For example, Brueckner (2001) presents a theoretical model demonstrating how international alliances are likely to lead to lower prices and increased traffic on interline routes (i.e. those linking the networks of two alliance partners). A subsequent paper by Brueckner (2002) estimates that the fare savings on interline routes due to codesharing and antitrust immunity are between eight and thirty percent. These papers suggest that by cooperatively setting prices on interlining itineraries, allying carriers can eliminate the "double marginalization" problem caused by each partner setting the price of their own segment without considering the impact on joint profits. Although these papers allow for the possibility that fares on gateway-to-gateway routes (i.e. "overlap" routes) may increase, empirical studies by Park and Zhang (2000) and Brueckner and Whalen (2000) fail to establish any such impact. To the contrary, Park and Zhang's (2000) study of North Atlantic overlap routes found that fares decreased by an average of $\$ 41$ on routes served by allying carriers. Similarly, a study of transatlantic "gateway-to-gateway" routes by the Department of Transportation (2000) found that average fares decreased 17\% between 1996 and 1999 in Open Skies markets compared to a decline of only $5.1 \%$ in non-Open Skies markets. More generally, the DOT's report concluded that:

In combination with individual airlines, multiple alliances of various types-from broad-based strategic alliances to more modest code-share alliances-are expanding geographically and creating ever-increasing numbers of overlap markets. This has created a more competitive transatlantic market structure. Thus, new flexibility for carriers to respond to marketplace demands has led to downward pressures on price, both due to increased supply and increased competitiveness. 
In summary, there would appear to be considerable evidence that Brock's concerns regarding increasing concentration due to international alliances are not well founded.

\section{Predatory behavior}

The second section of Brock's paper concerns the alleged predatory behavior of network airlines. In particular, Brock contends that "During the 1990s, the main carriers have repeatedly resorted to sharp, tightly focussed price cuts that corral low-fare independent carriers and prevent them from obtaining and expanding competitive footholds in important routes and markets." While it is true that there were a number of complaints by small, low-fare carriers during the 1990s alleging predatory behavior, Brock fails to note that no court has found any airline to be guilty of predation during that period. And although Brock correctly notes that the DOT considered issuing guidelines outlining new definitions of "exclusionary practices" (including predation), he fails to point out that the DOT subsequently decided against publishing these guidelines for fear that they would do more competitive harm than good. Moreover, a recent U.S. District Court decision examining the alleged predatory behavior of American Airlines against a number of smaller carriers found no predation and granted summary judgement in favor of American dismissing the predation claims. ${ }^{4}$ Indeed, the presiding judge on this case concluded that:

The government's claims in the present case fail because American did not price below an appropriate measure of cost, because it at most matched the prices of its competitors, and because there is no dangerous probability (even assuming below-cost pricing) of recoupment of American's supposed profits by means of supra-competitive pricing.

Finally, the rapid growth of numerous low fare airlines over the decade belies Brock's assertions that such carriers have systematically been prevented from entering important markets. Although a number of low fare airlines such as Carnival, Braniff and Western Pacific all ceased operating during the 1990s, a number of other low fare carriers including ATA, AirTran, and Frontier have all grown substantially. For example, AirTran and Frontier both began service in 1994, yet both have market capitalizations nearly two-thirds that of United Airlines. ${ }^{5}$ Another recent new entrant, JetBlue, has not only enjoyed rapid public acceptance but has also completed a highly successful initial public offering. Contrary to Brock, these successes appear to demonstrate that successful entry into the U.S. airline industry continues to be possible when based on a sound business strategy and a solid, experienced management team. ${ }^{6}$

\section{Changes in average airfares: $1990-2000$}

The final section of Brock's study focuses on changes in airline prices during the 1990s. Of the non-anecdotal evidence provided by Brock, two points deserve special attention. First, Brock correctly notes that the 1990s saw an increasing gap between leisure and

\footnotetext{
${ }^{4}$ U.S. vs. AMR Corporation, Case number 99-1180-JTM, U.S. District Court for the District of Kansas.

${ }^{5}$ As of May 16, 2002, the market capitalizations of AirTran, Frontier and United were roughly \$417 million, $\$ 483$ million and $\$ 658$ million respectively.

${ }^{6}$ As of May 16, 2002, JetBlue's market capitalization exceeded that of all network carriers except American and Delta.
} 
business fares. However, he also suggests that "inordinate discrimination in the fares charged [to] business travelers versus leisure flyers is further suggestive of an absence of effective competition." To support this claim, Brock presents data illustrating substantial differences between the "business" and "leisure" fares on six routes from Cincinnati, a Delta hub (see Table VI). Even on the most highly competitive routes, however, all airlines including low-fare, point-to-point airlines segment demand by using a number of restrictions or advance purchase requirements. For example, no fewer than seven different carriers offer non-stop service between Los Angeles (LAX) and Las Vegas, and the overwhelming majority of passengers traveling on this route are leisure passengers. ${ }^{7}$ Nevertheless, even Southwest Airlines offers ten different fares on this route based on age, time of travel, refundability, and time of purchase - the most expensive of which is priced three times that of their least expensive fare. ${ }^{8}$ Furthermore, it has been well-established that differential pricing allows airlines to simultaneously serve the differing needs of business and leisure travelers. For example, the Transportation Research Board (1999) found that:

Price discrimination allows carriers to cover both the operating and capital costs of providing the schedule-intensive service desired by business travelers, while filling empty seats with leisure travelers whose low fares at least cover their incremental, or marginal cost.

More generally, it is well known that in industries with large fixed costs, Ramsey pricing (or the practice of allocating fixed costs across consumers based on their relative price-elasticities) can be welfare maximizing. ${ }^{9}$ Moreover, as noted by Levine (2002), price discrimination need not imply market power.

A second main assertion made by Brock in this section also has the potential to mislead readers: it is the notion that airfares, on average, have risen in real terms over the past decade. In particular, Brock (2000) contends that:

More broadly, air fares are significantly outstripping airline costs as well as prices in the economy generally: Over the 1990-98 period, air fares rose 42 percent - significantly above the increase in the consumer price index for all goods and services (29 percent)...

Brock's assertion that real air fares have increased is based on an analysis of Bureau of Labor Statistics (BLS) data, which in turn is based on a complicated and somewhat opaque sampling procedure combining a number of data sources. Because it relies on Sabre's published fares as its source for prices, the BLS data overstate actual paid fares. This results from the fact that many of today's travelers receive substantial discounts off these published fares-in the form of corporate discount programs or "online" booking discounts, for example-neither of which are reflected in Sabre's published fares. Moreover, to construct a price index, the BLS needs to track a "basket" of airline services which attempts to hold product quality constant. Given the complexity of today's airline pricing, the BLS is forced to make a number of subjective estimates when tracking this basket. $^{10}$

\footnotetext{
${ }^{7}$ American, America West, United, Southwest, National, Hawaiian, and Delta all offer daily non-stop service between Los Angeles' LAX airport and Las Vegas. Source: OAG May 2002 Pocket Guide.

${ }^{8}$ Source: www.iflyswa.com as quoted on May 13, 2002. The unrestricted round-trip fare was priced at $\$ 176$ versus the "friends fly free" fare of $\$ 59$ round-trip per person (based on a purchase of two tickets). Similarly, American Airlines' unrestricted coach fare on this route is $\$ 511$ compared to its advance purchase restricted coach fare of \$95. Source: aa.com as quoted on May 15, 2002.

${ }^{9}$ See, for example, Transportation Research Board (1999).

${ }^{10}$ For example, the BLS states "When an airline discontinues a discount fare that is being priced, BLS substitutes the closest available alternative. Applicable restrictions may change, such as advance purchase
} 
Figure 1 compares the average nominal price per mile for air service nationwide with the Consumer Price Index from 1990-2000. As with our analysis of market shares, we base our analysis of prices on the DOT's DB1A database. In computing price per mile, we use the non-stop distance between the origin and destination, since passengers are not expected to be willing to pay more for circuitous routings. Figure 1 demonstrates that the nominal price per mile charged for air service declined from 18.8 cents per mile in 1990 to 18.6 cents per mile in 2000 . In contrast, general consumer prices as measured by the CPI, increased on average $2.8 \%$ a year during the 1990s. Thus, in real terms, and in stark contrast to data cited by Brock, the majority of passengers are paying significantly less for air travel today than they were in $1990 .{ }^{11}$

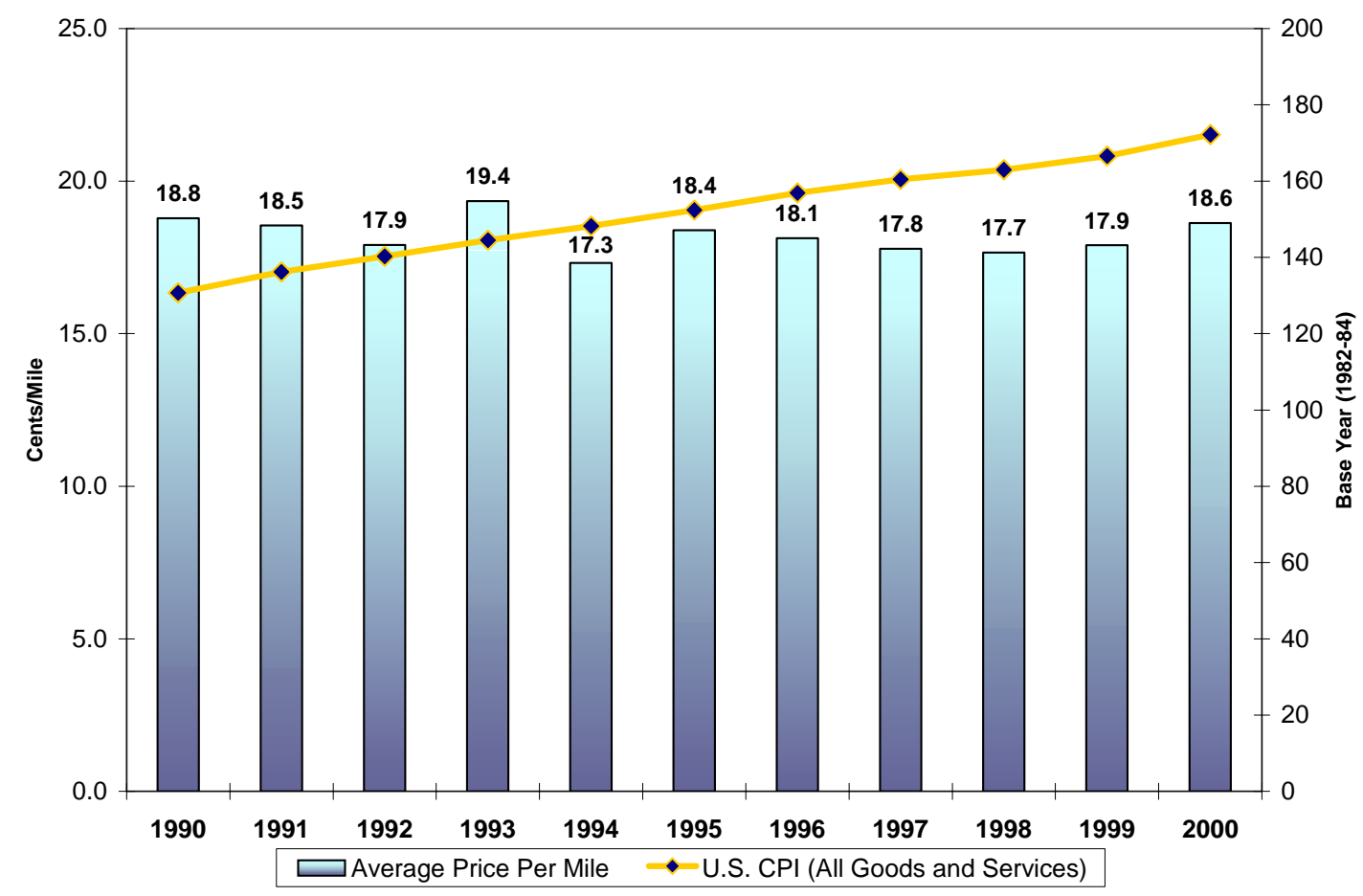

Notes: Domestic passengers excluding frequent flyer and interline tickets. Price per mile based on non-stop distance, excluding taxes and fees. CPI is All Urban Consumers, All Goods and Services. Source: U.S. DOT DB1A database and Bureau of Labor Statistics.

Figure 1: Average price per mile vs. CPI

It is also important to note that 2000 was a record year (in terms of revenues and passengers) for the U.S. airline industry, primarily due to the strength of the U.S. economy, which in turn resulted in strong demand by high yielding business travelers. Thus, we see that overall, nominal prices in 2000 were relatively high compared to prices throughout the latter half of the 1990s. In contrast, average fares for the first half of 2001 (the latest two quarters for which the DOT data are unaffected by the events of September 11th) declined

requirements, connecting airports, days of the week for which travel is valid, etc. When such changes occur, BLS estimates the value of the change." Source: How BLS Measures Price Changes for Airline Fares in the Consumer Price Index, Bureau of Labor Statistics.

${ }^{11}$ Our finding - that both real and nominal prices have declined throughout the 1990s - is consistent with that of the Transportation Research Board (1999) which studied average yields (price per revenue passenger mile) between 1990 and 1998. 
substantially along with the weakening economic conditions. For example, the average price per mile paid in the first six months of 2001 was 17.9 cents, compared to the 18.7 cents for the same period in 2000 , a decline of $4.2 \%$.

In summary, our analysis of DOT data finds no evidence that overall airfares have increased over the last decade. On the contrary, nominal fares declined slightly from 1990 to 2000 and consequently, real fares declined, on average, by over $30 \%$.

\section{Conclusions}

This paper has attempted to validate each of the three main developments cited by Brock in his recent overview article of the airline industry. If found to be true, Brock's findings would indeed be cause for concern. However, in attempting to replicate Brock's results using Department of Transportation data, we find no evidence of increasing national concentration or rising average prices. To the contrary, our analysis finds that the national market share of the network carriers has in fact been declining, not increasing over the past decade and overall prices have fallen steadily in real terms since 1990. Moreover, concerns regarding the negative impact of international alliances and predatory pricing appear to be largely unfounded and unsupported in the literature.

\section{References}

Borenstein, Severin. (1992), "The Evolution of U.S. Airline Competition," Journal of Economic Perspectives, 6: 45-73.

Brock, James (2000) “Industry Update: Airlines," Review of Industrial Organization, 16: 41-51.

Brueckner, Jan K. (2001) "The Economics of International Codesharing: An Analysis of Airline Alliances," International Journal of Industrial Organization, 19: 1475-1498, 2001.

Brueckner, Jan K. (2002) "International Airfares in the Age of Alliances: The Effects of Codesharing and Antitrust Immunity," Review of Economics and Statistics, forthcoming.

Brueckner, Jan K. and Tom Whalen (2000) "The Price Effects of International Airline Alliances," Journal of Law and Economics 43: 503-545.

Evans, W. \& Kessides, I. (1993) "Structure, Conduct and Performance in the Deregulated Airline Industry," Southern Economics Journal 59: 450-67.

Levine (2002) "Price Discrimination Without Market Power," Yale Journal of Regulation, 19(1): 2-36.

Morrison, S. \& Winston, C. (1995), "The Evolution of the Airline Industry," The Brookings Institution. 
Park, Jong-Hun, and Anming Zhang (2000) "An Empirical Analysis of Global Airline Alliances: Cases in the North Atlantic Markets," Review of Industrial Organization 16: 367-384.

Transportation Research Board (1999), "Entry and Competition in the U.S. Airline Industry: Issues and Opportunities," National Research Council, Special Report 255. Washington D.C., National Academy Press.

U.S. Department of Transportation (2000) "International Aviation Developments: Transatlantic Deregulation (Second Report)," Office of the Secretary. 